months. With regard to the more severely poisoned, we are still in doubt whether complete recovery ever takes place.

It is a relatively easy hazard to contain. Awareness of the severely toxic nature of the substance on the part of the management and workers is the principal factor in prevention of acrylamide poisoning.

We wish first to thank the managements of the seven factories who allowed us to study their methods of using acrylamide. In particular we are grateful to those directors of factories making flocculators who unearthed cases among their own staff. They could so easily have behaved very much less helpfully.

We thank Dr. J. C. Phemister for his permission to publish Case 1 and for his advice throughout on the neurological aspects. We thank also the following doctors for answering our letters promptly and giving every assistance they could to our understanding: C. L. Davidson, P. Knight, B. O. Porchetta, J. A. Price, J. V. Reuben, L. W. Smith, and T. Thorburn.

REFERENCES

Anon. (1967). Fap. F. Hyg., March, p. 68.

Auld, R. B., and Bedwell, S. F. (1967). Canad. med. Ass. F., 96, 652. Fujita, A., et al. (1960). ¥apan Medical Report, Feb. 20, p. 37. Fullerton, P. M., and Barnes, J. M. (1966). Brit. F. indusir. Med., 23, 210.

Kuperman, A. S. (1958). f. Pharmacol. exp. Ther., 123, 180. McCollister, D. D., Oyen, F., and Rowe, V. K. (1964). Toxicol. appl.

Patty, F. A. (1962). Industrial Hygiene and Toxicology, 2nd ed., vol. 2, pp. 1775, 1832. New York.

\title{
Fructose Intolerance
}

\section{J. A. BLACK,* M.D., F.R.C.P. ; K. SIMPSON, $†$ M.D., M.R.C.P.}

Brit. med. F., 1967, 4, 138-141

Fructose intolerance is a genetically determined disorder in which the giving of fructose or fructose-containing sugars such as sucrose causes severe hypoglycaemia, while the continued absorption of small amounts of fructose results in fatty infiltration and fibrosis of the liver. The condition was first described by Chambers and Pratt (1956), and Froesch et al. (1957) in Zürich demonstrated the biochemical response in affected individuals to a dose of fructose or sucrose. Since then more than 40 cases have been described, and it is probable that fructose intolerance is at least as common as is galactose intolerance. In all except one family (Wolf et al., 1959) the condition seems to have been inherited as an autosomal recessive.

This is a potentially fatal condition in infancy if untreated; in those infants who survive, hypoglycaemic symptoms may continue throughout childhood and even into adult life, and it is therefore equally important that the family doctor, the paediatrician, and the general physician should be aware of this easily treated disorder.

\section{Case 1}

The patient, a girl born on 19 March 1962, was the fourth child of healthy unrelated parents; birth weight $6 \mathrm{lb} .8 \mathrm{oz}$. (2.95 kg.). She was breast-fed for three days and later fed on various dried milks with the conventional additions of sucrose. On return home from the maternity hospital she began to vomit, lost weight, and became jaundiced. At the age of 1 month she was admitted to hospital. She was a pale, jaundiced baby with a blotchy face and a blood-stained nasal discharge. The abdomen was distended by ascites and by a moderately enlarged liver (two fingerbreadths below the costal margin).

Investigations.-Haemoglobin 8.8 g./100 ml. (61\%); W.B.C. $27,000 /$ cu. mm. (neutrophils $71 \%$ ). Serum bilirubin $5.5 \mathrm{mg} . / 100$ $\mathrm{ml}$. Serum alkaline phosphatase 22 units $/ 100 \mathrm{ml}$. ; thymol turbidity 1 unit; S.G.O.T. 140 units $/ 100 \mathrm{ml}$; S.G.P.T. 100 units $/ 100 \mathrm{ml}$. Serum proteins $3.5 \%$, with a lowering of albumin and $\beta$-globulin, and an elevated $\alpha_{1}$ - and $\gamma$-globulin. Urine normal to routine examination.

One week after admission a laparotomy was done (Mr. H. H. Nixon). There was much ascitic fluid and the liver was greenish brown with a finely granular appearance. A piece of liver was removed; part of this was sent for routine histological examination and the rest was kept in a deep freeze. The histological report on the liver (Dr. Barbara Ockenden) was as follows: "There is intra-

* Consultant Paediatrician, Sheffield Children's Hospital.

t Consultant Paediatrician, Leicester Area. lobular bile retention in the canaliculi, with widespread but patchy giant-cell transformation. There is a variable degree of sublobular cirrhosis. A little glycogen is present but there is no fatty change." A provisional diagnosis of giant-cell hepatitis was made, though galactosaemia was also considered, but was excluded by finding a normal activity of galactose-1-phosphate uridyl transferase in the infant's red cells.

After the laparotomy she improved. The urine at this time showed a gross amino-aciduria on two occasions with small quantities of galactose $(50$ and $12 \mathrm{mg} . / 100 \mathrm{ml}$.) and traces (less than $5 \mathrm{mg} . / 100 \mathrm{ml}$.) of glucose, sucrose, fructose, and lactose.

She was discharged at the age of 7 weeks weighing $8 \mathrm{lb} .5 \mathrm{oz}$. (3.77 kg.) but improvement was not maintained. At the age of 5 months she began to gain weight; by 8 months she weighed $14 \mathrm{lb} .10 \mathrm{oz}$. (6.63 kg.) and her liver was almost normal in size. Since her progress seemed much better than would have been expected of a child with a severe hepatitis the history was reviewed with her mother, who said that the baby had begun to thrive as soon as she had substituted glucose for sucrose in the feeds. She had done this because she had noticed that the patient's reaction to sucrose was similar to that of her first child (Case 2), whose history follows.

\section{Case 2}

This male child born on 26 September 1953 was breast-fed for one month and then changed to dried milk with the usual additions of sucrose. He did not take his feeds well and failed to gain weight on three different milks. A health visitor suggested that it was the sucrose which was upsetting him and advised the mother to use glucose. After this he gained weight but later developed a " screaming dislike" of sweet things, also carrots, peas, baked beans, fruit, and a variety of other foods.

A diagnosis of fructose intolerance in both children now seemed probable, and an oral fructose-tolerance test was performed by Dr. K. Simpson at Leicester Royal Infirmary (they had moved shortly after the diagnosis was suggested in London).

\section{Comment}

Case 1 was given $5 \mathrm{~g}$. of fructose $(0.5 \mathrm{~g} . / \mathrm{kg}$. body weight). She vomited soon after her test dose and was sleepy for the rest of the day. A urine specimen during the test contained fructose. The response to the fructose was characteristic of fructose intolerance (Fig. 1). Case 2 was given 13 g. of fructose $(0.5 \mathrm{~g} . / \mathrm{kg}$. body weight). He became pale and drowsy and felt sick. The chemical changes in his blood were also typical of fructose intolerance. 
A fructose-free diet was therefore prepared and the sheet was shown to the mother, but she reported that it contained little information which she and her family had not already worked out for themselves. At the time of writing both children were well and were growing normally. At the age of 3 years 11 months Case 1 weighed $35 \mathrm{lb}$. (15.9 kg.) and her height was $3 \mathrm{ft} .2$ in. $(96.5 \mathrm{~cm}$.), while Case 2, aged 12 years 5 months, weighed $88 \mathrm{lb}$. (40 kg.) and was $4 \mathrm{ft} .11 \frac{3}{4} \mathrm{in}$. (152 cm.) tall.

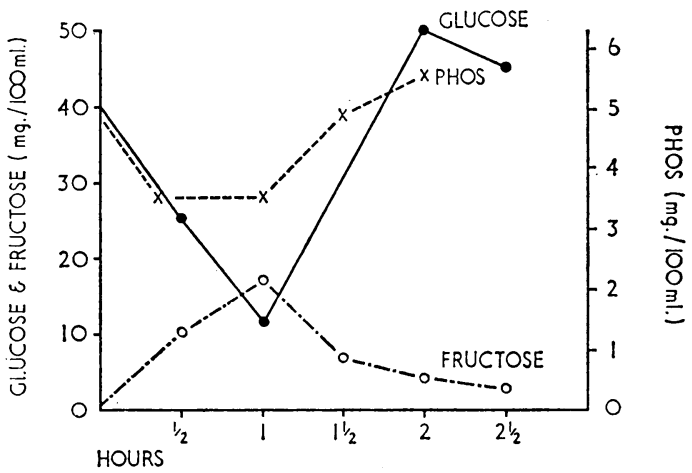

Fig. 1.-Case 1. Aged 1 year. Oral fructose tolerance test ; $5 \mathrm{~g}$. of fructose was given by mouth.

Subsequently the piece of liver from the biopsy preserved in the deep freeze at $-35^{\circ} \mathrm{C}$. was examined by Dr. A. D. Patrick in the Department of Chemical Pathology at the Hospital for Sick Children, London. Aldolase activities, with both fructose-1-phosphate and fructose-1-6-diphosphate as substrates, were estimated by the method of Leuthardt and Wolf (1955). The results (see Table) demonstrated a $50 \%$ reduction in the diphosphate aldolase activity and an almost complete absence of fructose-1-phosphate aldolase activity, giving a ratio of $6: 1$ instead of the normal ratio of approximately $1: 1$. Some of the same material was also examined by histochemical methods (Lake, 1965) and showed a reduction of aldolase activities with both fructose-1-phosphate and fructose diphosphate as substrates.

\begin{tabular}{|c|c|c|c|c|}
\hline & & \multicolumn{2}{|c|}{$\begin{array}{c}\text { Activity ( } \mu \text { moles NADH/min./g. Wet } \\
\text { Wt. of Liver) }\end{array}$} & \multirow{2}{*}{$\begin{array}{l}\text { Activity Ratio } \\
\text { F-1-6-P./F-1-P. }\end{array}$} \\
\hline & & F-1-P. Aldolase & F.-1-6-P. Aldolase & \\
\hline $\begin{array}{l}\text { *Control 1 } \\
\text { *Control } 2 \\
\text { Case 1 } \quad \cdots\end{array}$ & $\ddot{0}$ & $\begin{array}{l}0.90 \\
0.92 \\
0.08\end{array}$ & $\begin{array}{l}1 \cdot 00 \\
0 \cdot 83 \\
0 \cdot 49\end{array}$ & $\begin{array}{l}1 \cdot 1 \\
0 \cdot 9 \\
6 \cdot 1\end{array}$ \\
\hline
\end{tabular}

*ontrol specimens were stored
period as the specimen from Case 1 .

\section{Case 3}

This male child born on 16 March 1964, birth weight $6 \mathrm{lb} .11 \mathrm{oz}$ $(3.04 \mathrm{~kg}$.), was the second child, both parents being healthy and unrelated. He was breast-fed for two days; the feed was then changed to a dried milk with added sucrose. He started vomiting, and at the age of 7 weeks was admitted to the Children's Hospital, Sheffield, with a provisional diagnosis of pyloric stenosis. $\mathrm{He}$ weighed $7 \mathrm{lb} .1 \frac{1}{2} \mathrm{oz}$. (3.22 kg.) and looked wasted but not dehydrated; there was no evidence of pyloric stenosis. His urine was normal to routine testing. During the next month he continued to feed poorly and did not gain weight: at the age of 11 weeks his liver was enlarged to two fingerbreadths below the costal margin, and in the next two months it increased in size. His urine contained an unidentified reducing substance on one occasion. He was very ill, and it was decided to give him a fructose-free diet without any preliminary tolerance tests. On this diet there was a steady improvement, interrupted only by a further fall in weight when sucrose was added to his feeds in error. During this setback fructose was identified in his urine and the total reducing substances in his blood were $77 \mathrm{mg} . / 100 \mathrm{ml}$. with $45 \mathrm{mg} . / 100 \mathrm{ml}$. of glucose: a considerable proportion of the large difference of $32 \mathrm{mg} . / 100 \mathrm{ml}$. was thought to represent fructose (a specific method for fructose was not at this time available at the hospital). He finally returned home at the age of 6 months and has been gaining weight steadily (Fig. 2). His liver was normal in size.

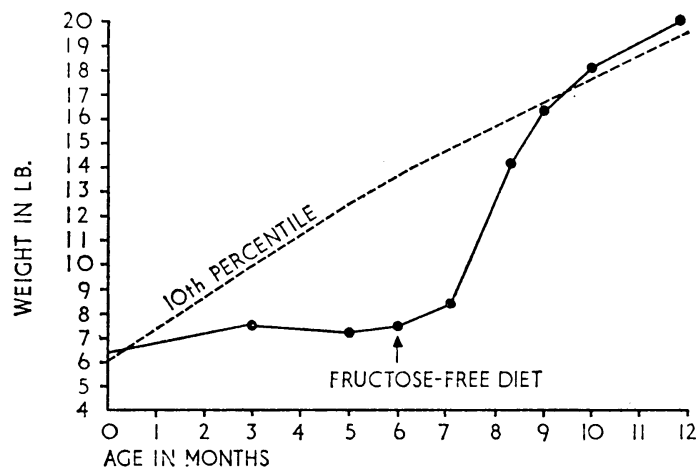

FIG. 2.-Case 3. Weight chart showing the effect of the introduction of $a$ fructose-free diet.

The diagnosis in this child was initially obscured by the fact that his elder sister (Case 4) was diagnosed at the age of 5 years as having glycogen storage disease and had had a liver biopsy at the age of 5 years. However, examination of her notes and the biopsy sections showed no real evidence of glycogen storage. Her history follows.

\section{Case 4}

The elder sister of Case 3, born 24 May 1953, birth weight $6 \mathrm{lb}$. $11 \mathrm{oz}$. (3.04 kg.), was breast-fed for four weeks, then changed to a dried milk with added sucrose. At the age of 7 weeks she was admitted to the City General Hospital, Sheffield, with vomiting thought to be due to pyloric stenosis, but this was not confirmed. At 3 months she weighed $8 \mathrm{lb} .4 \mathrm{oz}$. ( $3.74 \mathrm{~kg}$.) and her liver was three fingerbreadths below the costal margin. Her urine contained fructose on one occasion and a reducing substance, "not glucose," on another occasion. She was thought to have glycogen storage disease. At the age of 5 years a liver biopsy showed very marked fatty change, with a normal amount of glycogen. When the diagnosis of fructose intolerance was suggested in her younger brother the evidence for the diagnosis of glycogen storage disease was reviewed. On further questioning the mother said that the child had always avoided sweet things. She was then given a similar diet to that of her brother. It has not been possible to carry out any formal confirmation of the diagnosis in these children.

\section{Case 5}

A girl born on 30 September 1957, birth weight $7 \mathrm{lb}$. (3.18 kg.), was the first child of healthy unrelated parents. She was breast-fed for a few days and then changed to a dried milk. Her mother found that the addition of sucrose to the feeds upset her and therefore stopped adding it. She had always been noticed to have an aversion to sweet things. At the age of 7 years 4 months she attended the Children's Hospital, Sheffield, with a history of listlessness for a few weeks. Since she had started school dinners, which she disliked, she had been generally unwell.

She was a healthy-looking girl, of normal height and weight for her age ; the only abnormality was a firm liver enlarged to two fingerbreadths below the costal margin. The urine was normal and contained no reducing substance. It was decided to do an oral fructose-tolerance test. On 12 February 1965 she was given $12.5 \mathrm{~g}$. of fructose $(0.5 \mathrm{~g} . / \mathrm{kg}$. body weight). After one hour she felt faint and looked pale. The level of fructose rose slowly to a maximum of $24 \mathrm{mg} . / 100 \mathrm{ml}$. at one and a half hours and the blood inorganic phosphorus also fell: the blood glucose level fell sharply from a fasting level of $79 \mathrm{mg}$. to $30 \mathrm{mg} . / 100 \mathrm{ml}$. at one hour and $27 \mathrm{mg}$. at two hours. These results were regarded as typical of fructose intolerance. She seemed well shortly after the test was completed and was allowed to go home. One week later she refused food and two days later complained of abdominal pain: 12 days after the test she was slightly jaundiced and her liver was four fingerbreadths below the costal margin. The urine contained bilirubin and a 
slight excess of urobilin, but no fructose. Serum transaminases were raised (S.G.P.T. 920 units/100 ml., S.G.O.T. 480 units/100 $\mathrm{ml}$.), but other liver-function tests were normal. After this she improved slowly on a fructose-free diet, and one month later her liver was two fingerbreadths below the costal margin and transaminases were normal.

Two years after the diagnosis was made she was no longer listless, her liver was just palpable and felt normal. Her teeth had been examined by Mr. R. C. W. Dinsdale at the Charles Clifford Dental Hospital, Sheffield, and been found to be completely free of caries.

\section{Presentation}

The presenting symptoms of fructose intolerance are extremely varied. An infant with this condition will thrive normally as long as he is wholly breast-fed: as soon as feeds containing sucrose-that is, cane sugar or beet sugar-are given, vomiting occurs or the infant may refuse to feed after sucking for a few minutes. Severe neonatal jaundice with hepatomegaly may develop, with signs of acute liver failure, just as may occur in galactose intolerance; or the vomiting may be so severe as to suggest pyloric stenosis. The condition may be fatal in infancy (Sacrez et al., 1962 ; Levin and Snodgrass, 1965) unless the diagnosis is made promptly or the mother realizes, having had previously affected children, that glucose must be substituted for sucrose. Later the hepatomegaly may suggest glycogen storage disease. By the time school age is reached the child will have learned to exclude sweet things and root vegetables from his diet, but the necessity of eating school meals causes severe distress, which may be interpreted as a behaviour disorder or school phobia. In hypoglycaemic fits, particularly with hepatomegaly, fructose intolerance should always be considered (Levin and Snodgrass, 1965). Swales and Smith (1966) have reported fructose intolerance in an adult and have pointed out that the vague symptoms may often lead to a diagnosis of "neurotic ill-health."

\section{Diagnosis}

In many cases of fructose intolerance a detailed dietetic history may point to the correct diagnosis, and it is important not only that artificial milks and infant foods should be accurately labelled, showing the exact monosaccharide or disaccharide which they contain, but also that the physician should know what sugars are added to the feeds of the infant under his care.

It must be emphasized that the absence of fructose in the urine does not exclude fructose intolerance. Even if present, fructosuria will be missed if a glucose-specific (glucose-oxidase) method is used for screening urines. In fructose intolerance, glucose and other sugars may be present in the urine at the same time as fructose, and therefore in any suspected metabolic disorder it should never be assumed that glucose if present is solely responsible for a positive reducing reaction. Chromatography of the urine should be used to identify all the sugars present.

The symptoms in fructose intolerance are due predominantly to the severe hypoglycaemia which occurs after a dose of fructose; nausea, vomiting, and epigastric discomfort are common if the fructose is given orally. The diagnosis can be confirmed by a fructose-tolerance test or by estimating the activity of fructose-1-phosphate aldolase in fresh or frozen liver tissue obtained by biopsy. Fructose-tolerance tests can be performed after an oral dose $(0.5 \mathrm{~g}$. $/ \mathrm{kg}$.), but it has been shown that more satisfactory results can be obtained by an intravenous injection of half the oral dose (Cornblath et al., 1963). Characteristically the fructose level in the blood rises to or above 20 $\mathrm{mg} . / 100 \mathrm{ml}$.; the blood inorganic phosphorus falls, and this is followed by a rapid fall of blood glucose to a level at which symptoms or even fits or unconsciousness may occur; such severe hypoglycaemia can be rapidly reversed by an intravenous injection of glucose, which should be immediately available during the test. Another disadvantage of the fructose-tolerance test is the delayed development of liver damage, as occurred in our Case 5.

In view of these disadvantages of the tolerance test it is not surprising that a liver biopsy should be thought to be preferable. Our experience confirms what has previously been shown (Sacrez et al., 1962 ; Desbuquois, 1965), that orthodox histological examination of the liver may be extremely misleading, as the sections may show a " neonatal hepatitis" (Case 1), gross fatty change (Case 4), or early cirrhosis, and it would appear that there are no histological changes which are specific to fructose intolerance. Therefore the only useful investigation on biopsy material is an estimation of the fructose-1-phosphate aldolase activity in the liver.

In practice the ratio of liver aldolase activities with both fructose-1-6-diphosphate and fructose-1-phosphate as substrates is usually determined. This ratio (F.1-6-P./F.1-P), which is approximately 1 for normal liver, increases to 6 or greater in fructose intolerance due to the almost complete absence of fructose-1-phosphate aldolase activity (Schapira et al., 1961-2). The appreciable activity of fructose-1-phosphate aldolase on fructose diphosphate would account for the moderate decrease in aldolase activity which is observed with the diphosphate as substrate. A liver biopsy may well be the investigation of choice if adequate biochemical facilities are available, but it cannot be too strongly emphasized that neither a liver biopsy nor a fructose-tolerance test should be done when the patient is severely ill ; this applies particularly to the newborn infant. A trial of a fructose-free diet can be easily arranged, and a dramatic improvement (Case 3) may give confirmation of the probable diagnosis without in any way prejudicing the performance of a diagnostic test when the patient's condition has improved.

The evidence that in fructose intolerance there is a considerable reduction of fructose-1-phosphate aldolase activity in the liver is based on numerous reports on biopsy material (Desbuquois, 1965). Confirmation of the expected increase in fructose-1-phosphate in the liver of affected individuals has also been provided by Milhaud (1964) and Rossier et al. (1966). Apart from this primary defect (Fig. 3) the accumulation of fructose-1-phosphate in the liver appears to inhibit the activity of fructokinase (Froesch et al., 1959) and of fructose-1-6diphosphate aldolase (Desbuquois, 1965), causing, respectively, a rise in fructose in the extracellular fluids and the inhibition of gluconeogenesis. There is also a block in the release of glucose from the liver ; after a dose of fructose glucagon fails to produce its usual hyperglycaemic effect, though the glucagon effect is restored later (Cornblath et al., 1963). It has been suggested that this interruption of glucose release from the liver is due to a failure of phosphorolytic degradation of glycogen, resulting

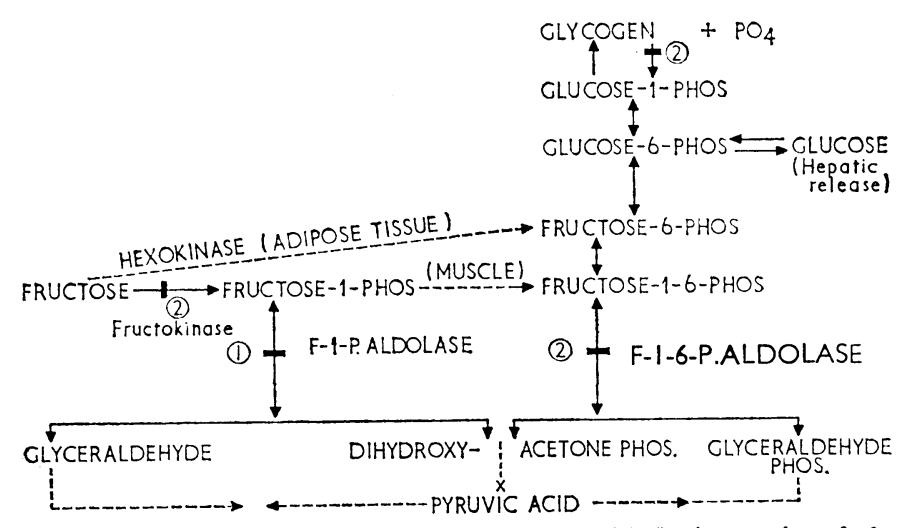

FIG. 3. - The metabolic pathways of fructose. (1) Indicates site of the primary block in fructose intolerance. (2) Indicates sites of secondary blocks. 
from the depletion of intracellular phosphate after its immobilization as fructose-1-phosphate, though this is still uncertain (Desbuquois, 1965). The severe hypoglycaemia resulting from a dose of fructose appears to be the resultant of a failure of glycogenolysis in the liver, with continued peripheral utilization of glucose by the tissues. The cause of the liver damage itself remains unexplained ; it is possible that the intrinsic metabolism of the liver cell is damaged, owing to depletion of cellular adenosine triphosphate (Levin et al., 1963).

\section{Treatment and Prognosis}

Treatment consists in the exclusion of sucrose and fructose from the diet, with the addition of ascorbic acid, as the daily intake is otherwise likely to be low. Difficulties often arise in the prescription of medicines or antibiotic syrups, and the patients and their doctors need to be warned specifically about this point.

Severe or fatal liver damage is likely to occur in infancy if the diagnosis is not suspected. As the case histories show, the diagnosis is commonly made by an observant mother if she has already had a similarly affected infant, but the exclusion of fructose-containing substances from the diet by the mother, or later by a self-selected diet, is not usually strict enough to prevent the development of hepatomegaly. It is probable, therefore, though there is as yet no certain evidence of this, that the fatty infiltration of the liver will in due course be followed by cirrhosis. Our own observations suggest that a strict fructose-free diet in children will cause a complete return to normality, though a long follow-up has not yet been possible.

\section{Summary}

Fructose intolerance is a genetically determined metabolic disorder inherited as an autosomal recessive. It is probably as common as the more widely recognized galactose intolerance.

In affected individuals fructose given orally or intravenously causes profound hypoglycaemia, with a rise of the level of fructose in the blood to $20 \mathrm{mg} . / 100 \mathrm{ml}$. or more. The essential abnormality is an absence of the liver enzyme fructose-1-P. aldolase. The condition may present in infancy as neonatal jaundice with hepatomegaly, or with vomiting and failure to thrive: in older children hypoglycaemic fits may occur or glycogen storage disease may be suspected on account of the enlarged liver. In adults the symptoms are less obvious, and may be dismissed as "neurotic ill-health."

The diagnosis is made by an oral or I.V. fructose tolerance test or by estimation of the activity of the specific aldolase in a fresh or frozen liver biopsy.

Treatment is by the exclusion of fructose and sucrose from the diet.

Five children with this condition are described.

We wish to thank Dr. A. D. Patrick, Department of Chemical Pathology, the Hospital for Sick Children, London, for his help in the investigation of Case 1 and for his advice in the preparation of this paper. We are also grateful to Professor Sir Alan Moncrieff, Dr. R. R. Gordon, and Dr. C. B. M. Warren for allowing us access to their clinical records.

\section{REPERENCES}

Chambers, R. A., and Pratt, R. T. C. (1956). Lancet, 2, 340

Cornblath, M., Rosenthal, I. M., Reisner, S. H., Wybregt, S. H., and Crane, R. K. (1963). New Engl. 7. Med., 269, 1271.

Desbuquois, B. (1965). Rev. int. Hépat., 14, 1.

Froesch, E. R., Prader, A., Labhart, A., Stuber, H. W., and Wolf, H. P.

(1957). Schweiz. med. W schr.; 87, 1168. H. W., and Woll, H. P. 14, 99 .

Lake, B. D. (1965). 7. roy. micr. Soc., 84, 489.

Leuthardt, F., and Wolf. H. P. (1955). Methods in Enzymology, edited by S. P.' Colowick and N. Kaplan, vol. 1, p. 320 . New York.

Levin, B., Oberholzer, V. G., Snodgrass, G. J. A. I., Stimmler, L., and Wilmers, M. J. (1963). Arch. Dis. Childh., 38, 220. and Snodgrass, G. I A I (1965). Clin. Pediat., 4, 605.

Milhaud, G. (1964). Arch. bras. Endocr. Metab. 13, 49.

Mossier, A., et al. (1966). Arch. franc. Pédiat., 23, 533 .

Rossier, A., et al. (1966) Mrch. Arch. Pranc. Pediat., 23, Sofatzis, J., and Dourof, N. (1962). Pédiatrie, 17, 875 .

Schapira, F., Schapira, G., and Dreyfus, J. C. (1961-2). Enzym. biol. clin. (Basel), 1,170 .

Swales, J. D., and Smith, A. D. M. (1966). Quart. F. Med., 35, 455.

Wolf, H. P., Zschocke, D., Wedemeyer, F. W., and Hübner, W. (1959). Klin. W schr., 37, 693.
Observations were made during the routine management of eight patients with advanced renal failure. All had radio- logical evidence of perihilar or interstitial pulmonary oedema, and all but one had dyspnoea, orthopnoea, and crepitations over the lungs. Further clinical, biochemical, and haemodynamic data are summarized in Table $I$. The haemodynamic data form part of those presented in a previous communication (Gibson, 1966). Biochemical estimations were performed by autoanalyser techniques. The total fluid loss during peritoneal dialysis was calculated from the cumulative balance of each exchange, and during haemodialysis from the weight loss of the patient. Drug therapy was not altered during the procedure, except in Case 8, where ethanol inhalations, morphine, aminophylline, and pentolinium were given without effect on the pulmonary oedema.

Phonocardiograms were recorded from the position along the left sternal edge where the splitting of the second sound was most obvious clinically. A Mingograf direct writing recorder was used, running at a paper speed of $100 \mathrm{~mm}$. per second. On account of the patients' dyspnoea, it was not always pos-

- Registrar, Medical Unit, Westminster Hospital, London S.W.1. Present appointment: Registrar, National Heart Hospital, London W.1. 